\title{
Review on Antimicrobial Agents
}

\author{
Mohammad Asif* \\ Department of Pharmacy, Guru Ram Das (PG) Institute of Management and Technolgy, India
}

Submission: February 18, 2017; Published: March 07, 2017

"Corresponding author: Mohammad Asif, Department of Pharmacy, Guru Ram Das (PG) Institute of Management and Technology, India

\begin{abstract}
Antimicrobial agent is a general term that is mainly concerned with antibiotics, antibacterial, antifungal, antiviral and antiprotozoans. The antimicrobial agent is a substance that kills or inhibits the growth of microorganism like bacteria, fungi and protozoan. Antimicrobial agents are capable of acting by two modes either by inhibiting the spread of the infectious agent (micro biostatic) or by killing it outright (microbiocidal). The treatment of using antimicrobial agents is currently facing its own limitation, 1,2 due to the development of resistance by the microbes over the period of time.
\end{abstract}

Keywords: Drugs; Activities; Antifungal; Antibacterial

\section{Introduction}

\section{Fungi}

The fungus is a eukaryotic organism which is classified as a separate kingdom from plants, animals and bacteria. The fungus kingdom is divided into one subkingdom, seven phyla, and ten subphyla having a vast diversity of taxa with varied ecologies, life cycle strategies, and morphologies ranging from single-celled aquatic hybrids to large mushrooms. They are omnipresent, comprising an estimated 250,000 species, of which only about 150 have reported to cause disease in humans. 3-5 Fungi contain unicellular, multinucleate, and multicellular forms and are classified on the basis of their reproductive spores and the nature of hyphae. They divide sexually or asexually or by both ways [1]. Fungi are almost entirely multicellular with exception of yeast Saccharomyces Cerviseae which is prominent unicellular fungus. Fungi are heterotrophic, deriving their energy from another organism, whether alive or dead. Fungi are eukaryotic protista differing from bacteria in many ways, as they posse's rigid cell wall containing chitin, manna, other polysaccharides and their cytoplasm membrane contains sterol. The major difference between fungal cells and plant cell is that fungal cell walls contain chitin, while plants contain cellulose [2-4].

\section{Mycology}

The discipline of biology which is devoted to the study of fungi is known as mycology. Mycology is concerned with the systematic study of fungi, including their genetic and biochemical properties [1-6]. Mycoses affecting humans can be divided into four groups based on the level of penetration into the body tissues as.

A. Superficial mycoses: Caused by fungi growing only on the outermost surface of the skin or hair. An example of a fungal infection is Tinea versicolor, a fungus infection that commonly affects the skin of young people, especially the chest, back, upper arms and legs.

B. Cutaneous mycoses or dermatomycoses: Caused by fungi growing only in the superficial layers of skin, nails, and hair causing infections commonly known as athlete's foot, jock itch, and ringworm.

C. Subcutaneous mycoses: Caused by fungi penetrating below the skin in the subcutaneous, connective, and bone tissue. The most common is sporotrichosis, occurring amongst gardeners and farmers who come in direct contact with soil.

D. Systemic or deep mycoses: Are caused by primary pathogenic and opportunistic fungal pathogens. The primary pathogenic fungi cause infection in a normal host; whereas, opportunistic pathogens require immune depressant host in order to establish infection (e.g., cancer, surgery and AIDS). The primary pathogens usually gain access to the host via the respiratory tract and include Coccidioides immitis, Histoplasma capsulatum, Blastomyces dermatitidis and Paracoccidioides brasiliensis. The opportunistic fungi invade via the respiratory and alimentary tract, and include Cryptococcus neoformans, Candida spp, Aspergillus spp, Penicillium marneffei, Zygomycetes, Trichosporon beigelii and Fusarium spp. 


\section{Organic and Medicinal Chemistry International Journal}

Mycology - Pathogenic Fungi: The study of pathogenic fungi is referred to as medical mycology. Pathogenic fungi cause disease in humans or other organisms. The commonly observed pathogenic fungi are enlisted below $[2,4]$.

A.Candida: Candida species are important human pathogens causing opportunist infections in immune compromised hosts (e.g. AIDS sufferers, cancer patients and transplant patients). The infections caused by the Candida species are difficult to treat and could be fatal. Candida species alone account to $30-40 \%$ death cases caused by the systemic infections. Fungal species of the genus Candida generally live communally on and in the human body. There is increase in development of drug resistance by Candida species to current therapies, motivating researchers to understand their genetics and discover new therapeutic targets.

B.Aspergillus: The aerosolized Aspergillus spores are found almost everywhere around human being and generally does not possess health issues. But still Aspergillus is capable of causing disease in three major ways: by the production of mycotoxins; by the induction of allergenic responses; and lastly by the localized or systemic infections. Aspergillus flavus produces mycotoxins, Aflatoxin which can act as both toxin and a carcinogen, having ability to contaminate foodstuff such as nuts.

C.Cryptococcus: The majorities of Cryptococcus species are found in the soil and generally do not cause disease in humans. Exception is Cryptococcus neoformans which cause disease in immune depressant patients like AIDS, causing a severe form of meningitis and meningo-encephalitis.

D.Histoplasma: Histoplasma capsulatum can cause histoplasmosis in humans, dogs and cats. The infection is usually due to inhaling the contaminated air and is prevalent in USA and Asia.

E.Pneumocystis: Pneumocystis jirovecii can cause a form of pneumonia in people with weakened immune systems, such as the elderly, AIDS patients and premature born children.

F.Stachybotrys: Stachybotrys chartarum can cause respiratory damage and severe headaches, in houses that are persistently damp.

a.Fungal Infection Prominent In Particular Diseases: The association of most commonly occurring fungi along with the patient suffering from the particular disease is enlisted below,

i. Candida species, Aspergillus species, Phycomyces species: Leucopenia.

ii. Zygomyces, Rhizopus, Mucor, Absidia: Diabetes.

iii. Candida, Cryptococcus, Histoplasma: Malignancies and Hodgkin's disease.

iv. Candida, Cryptococcus, Histoplasma: AIDS.

b.Clinically Significant Fungi and The Site They Affect: The pathogenicity and virulence of fungi causing infections, in humans is major concern in clinical world which focuses on the major causative agents of disease, particularly Candida, Cryptococcus and Aspergillus spp. The large diversity of potentially harmful fungi existing outside these groups, though rare may still posse's potential to be more important than the common clinical fungi. The site affected by the clinically significant fungi are enlisted as below,

i. Malassezia furfur and Exophiala werneckii: Superficial skin.

ii. Piedraia hortae and Trichosporon beigelii: Hair.

iii. Microsporum species: Skin and hair.

iv. Epidermophyton species: Skin and nails.

v. Trichophyton species: Skin, hair and nails.

vi. Sporothrix schenckii, Cladosporium species: Chromoblastomycosis.

vii. Histoplasma capsulatum, Penicillium species: Systemic respiratory.

viii. Blastomyces dermatitidis: Subcutaneous/respiratory.

ix. Cryptococcus neoformans: Respiratory/CNS.

c.Antifungal Agents: The antifungal agents are classified according to their mode of interfering with

I. Cell wall synthesis,

II. plasma membrane integrity,

III. Nucleic acid synthesis,

IV. Ribosomal function.

The (Figure 1) gives us brief idea about the mode of action antifungal drugs [4-10].

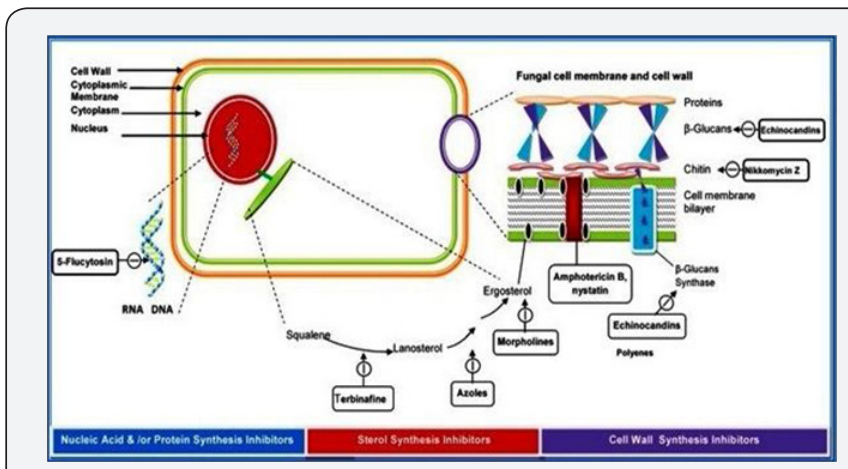

Figure 1: Classification of antifungal agents by their mode of action [10].

d.Systemic Antifungal Drugs:

i. Polyenes antibiotics: Amphotericin B.

ii. Azole derivatives:

iii. Imidazole: Ketoconazole, Miconazole. 


\section{Organic and Medicinal Chemistry International Journal}

iv. Triazole: Fluconazole, Itraconazole, Voriconazole, Posaconazole, Ravuconazole.

v. Echinocandin: Capsofungin, Anidulafungin, Micafungin.

vi. Antimetabolite: Flucytosine (5-FC).

vii. Nikkomycin

viii. Topical Antifungal Drugs:

I. Polyene antibiotics: Amphotericin B, Nystatin, Hamycin, Natamycin, Rimocidin, Hitachimycin, Filipin.

II. Azoles: Clotrimazole, Ketoconazole, Miconazole, Econazole, Butaconazole, Oxiconazole, Sulconazole, Fenticonazole, Isoconazole, Bifonazole, Terconazole.
III. Others: Tolnaftate, Undecyclinic acid, Povidone iodine, Triacetin, Gentian violet, Sodium thiosulphate, Cicloporoxolamine, Benzoic acid, Quinidochlor.

IV. Systemic Antifungal Drugs for superficial infections:

i. Heterocyclic benzofurans: Corticofunvin, Griseofulvin.

ii. Allylamine: Terbinafine, Butenafine, Naftifine.

\section{Class of Drug With General Mechanism Of Action}

The general mechanism of action of the drug depending upon its class is shown in (Figure 2) [11] and the drugs are as enlisted below $[1,3,4]$.

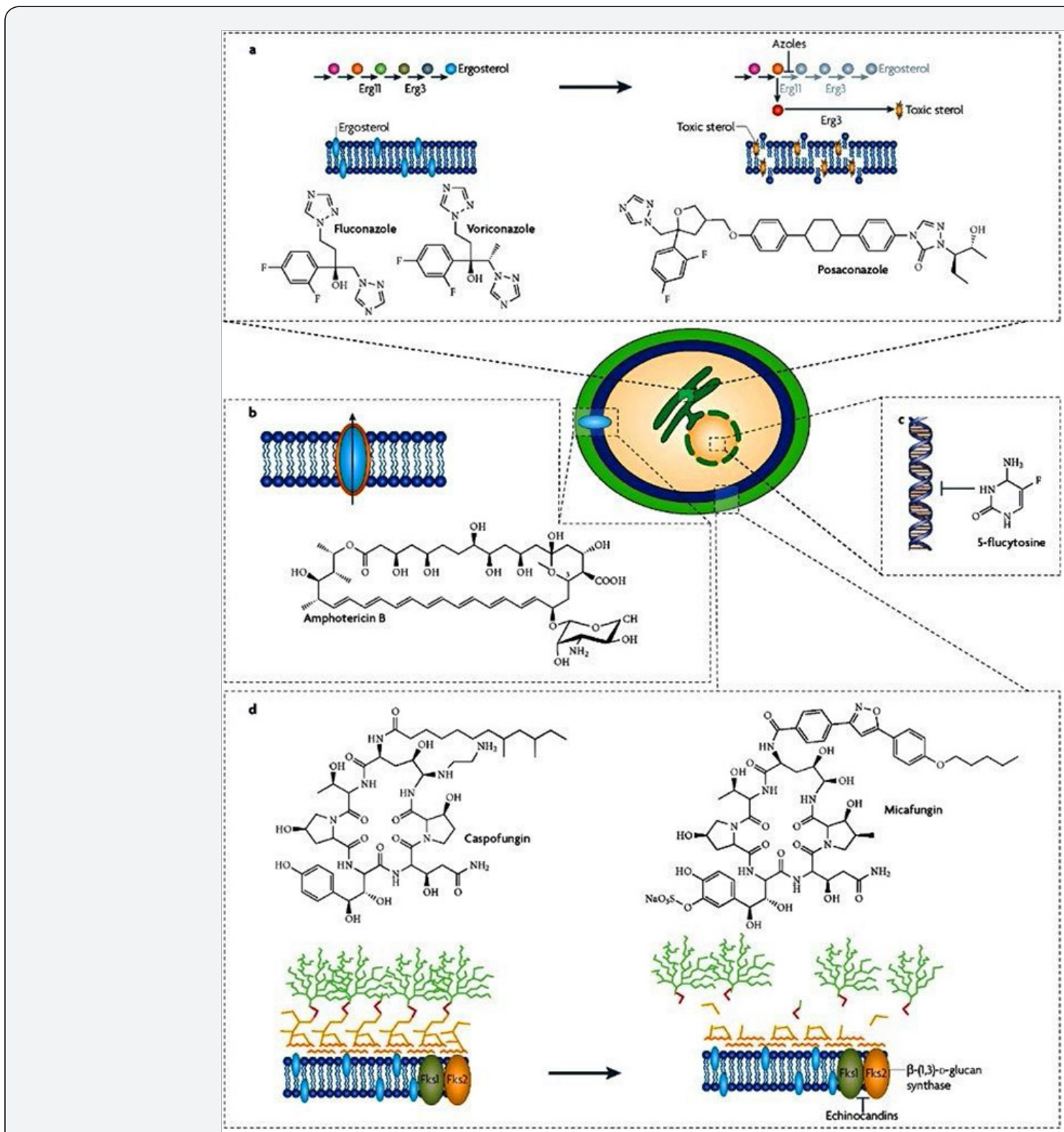

Figure 1: Classification of antifungal agents by their mode of action [10]. 


\section{Organic and Medicinal Chemistry International Journal}

\section{Griseofulvin}

The Griseofulvin was the earliest known inhibitory agent specific to fungal species. The Griseofulvin binds to tubulin, interfering with the functioning of microtubule and thus inhibiting mitosis. It binds to keratin in keratin precursor cells and makes them resistant to fungal infections. It is only when hair or skin is replaced by the keratin-Griseofulvin complex that the drug reaches its site of action.

\section{Flucytosine}

Flucytosine works as an antifungal agent by the conversion to 5-fluorouracil within target cells by cytosine deaminase, thereby inhibiting synthesis of DNA through effects on thymidylate synthase in fungi. For this mechanism of action, the target cells must possess certain enzymes like cytosine permease to internalise the flucytosine molecule, cytosine deaminase to convert it to 5-fluorouracil and uracil phosphoribosyl transferase to convert 5-fluorouracil into a substrate for nucleic acid synthesis. The use of flucytosine is restricted to pathogenic yeasts (Candida species and Candida neoformans) as majority of the filamentous fungi lack these enzymes.

\section{Polyenes}

The mode of action of polyene is different than other antifungal agents, instead of inhibiting an enzyme, it binds to ergosterol, which is the principal sterol in fungal membranes, thereby perturbing membrane function to the point of causing leakage of cellular contents. As with other polyene antifungal, Amphotericin B associates with ergosterol, forming a transmembrane channel that leads to monovalent ion $(\mathrm{K}+, \mathrm{Na}+$, $\mathrm{H}+$ and $\mathrm{Cl}-$ ) leakage, which leads to fungal cell death.

\section{Azoles}

The largest and most widely used class of antifungal agents is that of the azole-antifungals. Azoles inhibit 14- $\alpha$ demethylation of lanosterol in ergosterol biosynthetic pathway. This inhibition prevents the conversion of lanosterol to ergosterol, which is an essential component of the fungal cytoplasm membrane and subsequent accumulation of $14 \alpha$-methyl sterols.

\section{Allylamines}

At this moment there are two allyamines naftifine and terbinafine, and one thiocarbamate antifungal, tolnaftate which are in clinical use. They are inhibitors of squalene epoxidase an enzyme that is part of early stage of fungal cell membrane synthesis pathway. It prevents conversion of squalene to lanosterol, in turn ergosterol cannot be synthesized.

Table 1: Antifungal agents: Principal mode of action and resistance mechanism of fungal pathogens [15].

\begin{tabular}{|c|c|c|c|}
\hline Antifungal & Spectrum/comments & Mode of action & Mechanism of resistance \\
\hline $\begin{array}{c}\text { Polyenes } \\
\text { Amphotericin B }\end{array}$ & $\begin{array}{c}\text { Broad activity against Candida spp, } \\
\text { Crypto coccus neoformans } \\
\text { and filamentous fungi }\end{array}$ & $\begin{array}{c}\text { Binding to } \\
\text { Ergosterol }\end{array}$ & $\begin{array}{c}\text { Alteration in ergosterol } \\
\text { biosynthesis. }\end{array}$ \\
\hline
\end{tabular}

\section{Echinocandin}

The class of Echinocandin compounds is the fungal secondary metabolites, comprising a cyclic hex peptide core with a lipid side chain responsible for antifungal activity. The three commonly used Echinocandin, Anidulafungin, Capsofungin and Micafungin, inhibit the synthesis of cell wall $\beta-1,3$ glucan polysaccharides in the cell wall.

\section{Sordarins}

The sordarin family of compounds is characterized by a unique tetra cyclic diterpenes core. Sordarins selectively inhibit fungal protein synthesis by stabilizing the ribosome/EF2 complex. This unusual bioactivity makes sordarin a promising candidate for the development of new fungicidal agents.

\section{Antifungal Resistance}

The development of drug resistance in fungi is a broad concept, which describes failure of current antifungal therapy to overcome the fungal infection. The antifungal therapies are designed to eradicate fungal infection by various mechanisms of action, like by disrupting their reproductive capabilities, destroying the cell walls, or by modifying the fungal DNA and altering the cell functioning. Antifungal resistance has been traditionally classified as [12-14],

a.Primary (intrinsic), present before the exposure to antifungal.

b.Secondary (acquired), developing after the exposure to antifungal owing to stable or transient genotypic alterations.

c.Clinical resistance, it can be classified as third type of antifungal resistance, which cover the progress or decline of an infection by a fungal isolate that seems to be fully susceptible to the antifungal therapy used for the treatment of infection during testing. In the last decade, microorganisms are becoming drug resistant at a much faster rate than the rate of discovery of new drugs. The drug resistance of fungi is importunately observed in patients with weak immune system suffering from diseases like AIDS and cancer. The researchers thus face a major challenge to develop new, safe and more effective antifungal taking into account the increase in opportunistic infections in the immune compromised host. This can be overcome by the discovery of new drugs acting by novel mechanisms of action. The (Table 1) mentioned below, highlights the antifungal agents, their principal mode of action and the resistance mechanism of the fungal pathogens. 


\section{Organic and Medicinal Chemistry International Journal}

\begin{tabular}{|c|c|c|c|}
\hline $\begin{array}{c}\text { Pyrimidine } \\
\text { 5-fluorocytosine } \\
\text { (5-FC) }\end{array}$ & $\begin{array}{l}\text { Active against } \\
\text { Candida spp. and } \\
\text { Cryptococcus spp. }\end{array}$ & $\begin{array}{l}\text { Impairment of } \\
\text { nucleic acid } \\
\text { biosynthesis }\end{array}$ & $\begin{array}{l}\text { Decreased } \\
\text { Uptake of 5-FC. }\end{array}$ \\
\hline $\begin{array}{l}\text { Azoles } \\
\text { 1. Fluconazole }\end{array}$ & $\begin{array}{l}\text { Active against } \\
\text { Candida spp. and } \\
\text { Cryptococcus spp. }\end{array}$ & \multirow{4}{*}{ 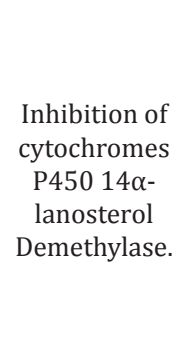 } & \multirow{4}{*}{$\begin{array}{l}\text { 1.Upregulation } \\
\text { of multi drug } \\
\text { transporter } \\
\text { genes. } \\
\text { 2. Target alterations. } \\
\text { 3.Alteration in } \\
\text { ergosterol } \\
\text { biosynthetic } \\
\text { Pathway. }\end{array}$} \\
\hline 2. Itraconazole & Active against filamentous fungi. & & \\
\hline 3. Voriconazole & $\begin{array}{l}\text { Enhanced activity against } \\
\text { filamentous fungi. }\end{array}$ & & \\
\hline 4. Posaconazole & $\begin{array}{l}\text { Related to itraconazole, but } \\
\text { Comparatively more active. }\end{array}$ & & \\
\hline Allylamines & $\begin{array}{c}\text { Terbinafine } \\
\text { Active against most } \\
\text { dermatophytoses }\end{array}$ & $\begin{array}{l}\text { Inhibition of } \\
\text { squalene } \\
\text { epoxidase }\end{array}$ & Unknown \\
\hline Morph lines & $\begin{array}{c}\text { Amorolfine } \\
\text { Active against most } \\
\text { dermatophytoses }\end{array}$ & $\begin{array}{l}\text { Inhibition of } \\
\text { sterol } \\
\text { reductase and } \\
\text { isomers. }\end{array}$ & Unknown \\
\hline Echinocandins & $\begin{array}{c}\text { Caspofungin } \\
\text { Active against Candida spp. }\end{array}$ & $\begin{array}{l}\text { Inhibition of } \\
\text { the cell wall } \\
\text { synthesis }\end{array}$ & Unknown \\
\hline
\end{tabular}

\section{Historic Perspective}

Historically, serendipity has often played an important role in scientific discoveries; classic example of which can be that of screening of dyes which led to the use and establishment of sulfanilamides as antibacterial. In 1903, de Beurmann and Gougerot were the first to discuss the use of potassium iodide to treat sporotrichosis. Whitfield in 1907 treated superficial fungal infections by using ointment [10-16]. In the mid 1940s sulfonamides were used to treat paracoccidioido mycosis though they had limited efficacy towards fungistatic properties and required.

longer times for treatment with high relapse rate. This was followed by the commercial use of penicillin in the 1940s. In rapid succession, came the discovery and development of streptomycin in 1944 and benzimidazole the first azole to have notable antifungal activity was discovered in 1944. It was followed by the discoveries of chloramphenicol in 1947 and chlortetracycline in 1948. In 1948 hydroxyl stilbamidine, an antiprotozoal agent having antifungal action was used to treat blastomycosis.

In 1951 Hazen and Brown, discovered the first polyene antibiotic called nystatin, commonly used topical and oral polyene. In 1952 substituted benzimidazole compounds were found to have antifungal properties. The macrolides were developed in 1952 having bacteriostatic properties. In 1956 Gold et al. reported the antifungal properties of the polyene Amphotericin B, which was the first significantly effective systemic antifungal. It became the standard and soon it replaced hydroxyl stilbamidine. Amphotericin B enjoyed the prime status of only antifungal agent available to treat systemic mycoses for nearly decade against which newer therapies for systemic mycoses were compared.

In 1957 Flucytosine, was developed as an antifungal agent who had failed to provide favorable results for the use as cytostatic agent. The use of flucytosine as a monodrug often developed fungal resistance which led to use in combination with Amphotericin B to overcome the resistance. The first significant oral antifungal agent Griseofulvin was developed in 1958, which became available for the treatment of superficial mycoses. Before Griseofulvin, the treatment of superficial dermatophytoses was only by the topical drugs which were not especially effective against tinea capitis and onychomycosis. The semi-synthetic penicillin's, cephalosporin's and glycopeptides were developed from 1958 onwards. The development of chlormidazole as a $5 \%$ cream in 1958 , was beneficial over wide range of cutaneous mycoses.

In the 1960s thiabendazole and mebendazole were reported to have antifungal and antihelminthic properties. In 1969 the imidazoles, clotrimazole and miconazole were introduced, which was soon followed by econazole in 1974 . The allylamines discovered in 1974 are the other classes of antifungal agents that have a significant impact on antifungal therapy especially for superficial dermatomycoses, including onychomycosis. Ketoconazole was developed in 1977 and since has become the standard among the azoles. In the mid-1980s two broad-spectrum, 


\section{Organic and Medicinal Chemistry International Journal}

orally available triazoles, fluconazole (1982) and itraconazole (1984) were discovered. Between 1990-1999 to develop new antifungal agents and resulted into introduction of three azoles Voriconazole (2000)-Pfizer, Posaconazole (2005)-ScheringPlough, Ravuconazole (2007)-Bristol-Myers Squibb) and three echinocandins (Caspofungin (2002)-MSD, Anidulafungin(2004)Astellas-Pfizer, Micafungin (2006)-Fujisawa) for their clinical use.

\section{Antifungal Drug Market: Current \& Future Scope 11,} $16,17$.

\section{Current Market Scenario}

The antifungal drugs in the market are compromised of four established classes-polyenes (e.g. Amphotericin B), azoles (e.g. fluconazole and itraconazole), allylamines (e.g. terbinafine) and the introduced echinocandins (e.g. Capsofungin). Of these classes, only the first three are in use to treat systemic fungal infections. This market is predominated by the azoles, the most successful of which is Fluconazole, which was first launched in the mid-1980s by Pfizer pharmaceuticals, and is marketed as Diflucan. The toxicity problems of Amphotericin B have been overcome to a little extent by the development of liposome based formulations, the most successful of which is Gilead's Ambisome, but these formulations are generally very costly. Amphotericin was successfully replaced by fluconazole to treat invasive candida infections. Johnson \& Johnson's marketed product Sporanox (Itraconazole) is suffering in sales due to lack of new intravenous formulation. Pfizer's Vfend (Voriconazole) and Schering's Posaconazole, the azoles with improved spectrum and activity will make further inroads into the Amphotericin market. A new class of antifungal drug that has emerged recently is the echinocandins. The first representative of this is Capsofungin, which is marketed by Merck as Candida in 2002 for treatment of invasive Aspergillosis, having superior activity over Amphotericin B. The second Echinocandin; Micafungin was launched as Funguard in 2002 by Fujusawa.

\section{Future Market Scenario}

Fungi are highly resistant eukaryotic microorganisms, and are becoming drug-resistant at an alarming rate to the approved compounds and some therapies later in clinical development. Despite the commercial success of the azoles, the drug interaction issues are a major impediment to the use of the azoles Voriconazole, itraconazole and Posaconazole. The interactions with cancer chemotherapy agents and immune suppressants are particularly difficult to handle clinically. On the other hand each year new pathogenic, mainly filamentous fungi are identified highlighting the need for broad spectrum coverage. Thus the rapidly increasing market of antifungal drugs have made the research and development of the newer and more effective antifungal agents of prime interest to both the industries and also to the academician around the globe.

\section{Reference}

1. www.doctorfungus.org.

2. Anantnarayan R, Paniker C J (2007) Textbook of Microbiology ( $7^{\text {th }}$ ed). Orient Longman pp: 665.

3. Tripathi K D (2004) Essential of Medical Pharmacology ( $5^{\text {th }}$ ed), New Delhi India, Pharmaceutical technology pp: 875.

4. Williams D A, Lemke T L, (2002) Foye's Principles of Medicinal Chemistry, ( $5^{\text {th }}$ ed), Philadelphia (USA): Lippincott Williams and Wilkins 712.

5. Ronald P K, Jean L Bolognia, Joseph L Jorizzo (2008) Dermatology (2 $2^{\text {nd }}$ ed). Dermatology Online Journal 2432-2625.

6. Frank C 0, Brown A J, Gow N A (2003) Trends in Microbiology 11: 272 279.

7. Brunton L, Lazo J, Parker K (2006) Goodman and Gilman's The Pharmacological Basis of Therapeutics 11th Ed. Permanente J 10(3).

8. Nadalo D M (2006) The J of Family Practice 55: 256-258.

9. Kradin R L, Mark EJ (2008) The pathology of pulmonary disorders due to Aspergillus spp. Arch Pathol Lab Med 132(4): 606-614.

10. Kathiravan M K, Amol B Salake, Aparna S Chothe, Prashik B Dudhe, Rahul P Watode et al. (2012) The biology and chemistry of antifungal agents: A review. Bioorg Med Chem 20: 5678-5698.

11. Cowen L E (2008) The evolution of fungal drug resistance: modulating the trajectory from genotype to phenotype. Nat Rev Micro 6: 187-198.

12. Gauwerky K, Claudia Borelli, Hans C Korting (2009) Targeting virulence: A new paradigm for antifungal. Drug Disc Today 14(3-4): 214-222.

13. Gupte M, P Kulkarni, B Ganguli (2002) Antifungal antibiotics. Appl Microbiol Biotech 58: 46-57.

14. Sanglard D (2002) Resistance of human fungal pathogens to antifungal drugs. Curr Opin Micro 5(4): 379-385.

15. Gupta A K, Daniel N Sauder, Neil H Shear (1994) Antifungal agents: An overview. Part I. J Am Acad Derm 30(5): 677-698.

16. Crandall M A (2012) Pharmaceuticals: Antifungal Drugs: Technologies and Global Markets. Report code: PHM029D. 


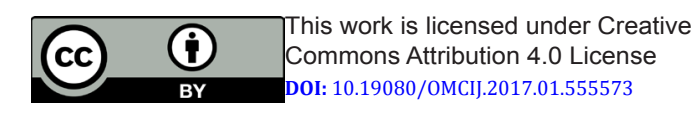

Your next submission with Juniper Publishers will reach you the below assets

- Quality Editorial service

- Swift Peer Review

- Reprints availability

- E-prints Service

- Manuscript Podcast for convenient understanding

- Global attainment for your research

- Manuscript accessibility in different formats

( Pdf, E-pub, Full Text, Audio)

- Unceasing customer service

Track the below URL for one-step submission https://juniperpublishers.com/online-submission.php 